\title{
Is marine debris ingestion still a problem for the coastal marine biota of southern Brazil?
}

\author{
Paula S. Tourinho, Juliana A. Ivar do Sul *, Gilberto Fillmann \\ Laboratório de Microcontaminantes Orgânicos e Ecotoxicologia Aquática, Instituto de Oceanografia, Universidade Federal do Rio Grande - FURG, C.P. 474, \\ CEP 96201-900, Rio Grande, RS, Brazil
}

\section{A R T I C L E I N F O}

\section{Keywords:}

Marine pollution

Plastic

Chelonia mydas

Procellariiformes

Sphenisciformes

Beach survey

\begin{abstract}
A B S T R A C T
The accumulation of synthetic debris in marine and coastal environments is a consequence of the intensive and continuous release of these highly persistent materials. This study investigates the current status of marine debris ingestion by sea turtles and seabirds found along the southern Brazilian coast. All green turtles ( $n=34$ ) and $40 \%$ of the seabirds ( 14 of 35 ) were found to have ingested debris. No correlation was found between the number of ingested items and turtle's size or weight. Most items were found in the intestine. Plastic was the main ingested material. Twelve Procellariiformes (66\%), two Sphenisciformes (22\%), but none of the eight Charadriiformes were found to be contaminated. Procellariiformes ingested the majority of items. Plastic was also the main ingested material. The ingestion of debris by turtles is probably an increasing problem on southern Brazilian coast. Seabirds feeding by diverse methods are contaminated, highlighting plastic hazard to these biota.
\end{abstract}

(c) 2009 Elsevier Ltd. All rights reserved.

\section{Introduction}

The accumulation of synthetic debris in marine and coastal environments is a result of the intensive and continuous release of these highly persistent materials. Once in the environment, marine debris can impact significantly on wildlife, for example, via entanglement and ingestion. During recent decades the ingestion of marine debris by seabirds, turtles, mammals and fishes has been widely reported (Balazs, 1985; Ryan, 1987; Laist, 1997). Reports attributing seabird and sea turtle mortality to debris ingestion are uncommon (Balazs, 1985; Colabuono et al., 2009), although complete obstruction of the gastrointestinal tract can lead to an animal's death (Bjorndal et al., 1994; Pierce et al., 2004). Sub-lethal effects, such as partial obstruction of the gastrointestinal tract and reduction of feeding stimulus, are more likely to be the major threats in the long-term (Ryan, 1987; Bjorndal et al., 1994; Bjorndal, 1997; Spear et al., 1995; McCauley and Bjorndal, 1999).

The coastal zone of southern Brazil is an important habitat for resident and seasonal migrant animals. Juvenile green sea turtles use the area to forage and grow during the austral summer and spring (Soto and Beheregaray, 1997). Eighty-three species of pelagic and coastal seabirds also use these beaches and the surrounding area primarily for feeding (Vooren, 1997). Pelagic seabirds (40\% of the 83 species) have a seasonal migratory behaviour and occur in oceanic and coastal waters in Brazil, while coastal seabirds

\footnotetext{
* Corresponding author. Tel.: +55 533233 6738; fax: +55 5332336601 .

E-mail address: julianasul@gmail.com (J.A. Ivar do Sul).
}

(60\%) inhabit shore areas, feeding in the swash zone (Vooren, 1997). Both pelagic and coastal seabird species migrate. Short-distance migratory seabirds travel to breeding sites along the Brazilian coast, but they are found all year long on the southern Brazilian coastline. Long-distance migratory seabirds travel between hemispheres (trans-equatorial migration) or from higher to lower latitudes during the austral winter (austral migration) (Vooren, 1997). Thus seabirds arriving at the beaches of southern Brazil will have had exposure to marine debris from a wide area.

This study describes patterns of marine debris ingestion by green sea turtles and different orders of seabirds found stranded at the southern Brazilian coast.

\section{Methods}

\subsection{Study area}

These surveys were conducted over $350 \mathrm{~km}$ of beaches from Peixe Lagoon $\left(31^{\circ} 20^{\prime} \mathrm{S}\right)$ in the southernmost state of Brazil (Rio Grande do Sul) to the Brazilian border with Uruguay $\left(33^{\circ} 45^{\prime} \mathrm{S}\right)$ (Fig. 1). The area has exposed sandy beaches with a northeastsouthwest orientation and is relatively undeveloped, with tourism activities in some areas during the summer (Esteves et al., 2002).

\subsection{Green turtles}

A total of 34 green turtles found stranded on the beach between December 2006 and March 2007 were identified and measured (i.e. 


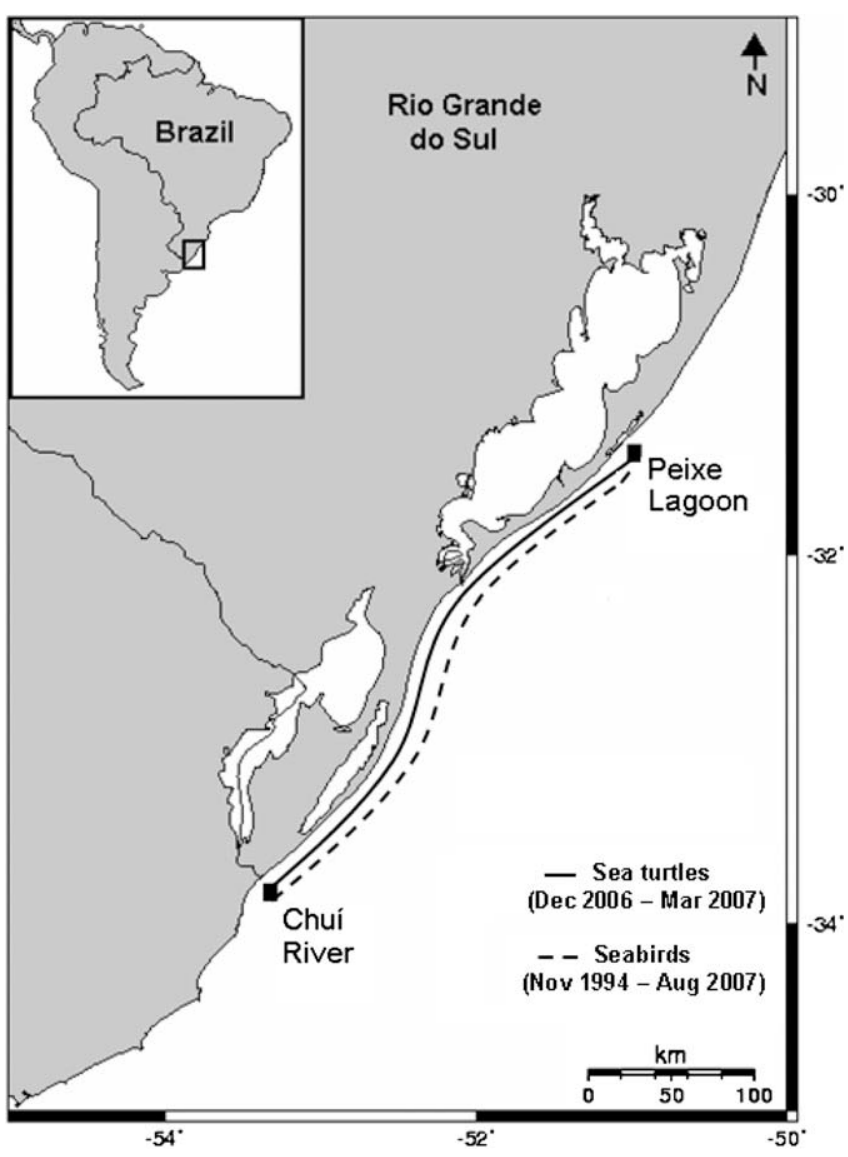

Fig. 1. The study beach between Peixe Lagoon and Chuí River on the Rio Grande do Sul coast, southern Brazil.

curved carapace lengths (CCL) and, for fresh samples, weight). Each gastrointestinal section (oesophagus, stomach and intestine) was analyzed separately. Items of marine debris were counted, weighed $(\geqslant 0.01 \mathrm{~g}$ ), and classified by type (virgin plastic pellet, soft plastic fragment, hard plastic fragment, straw, fishing line, fishing rope, polystyrene, fishing net, rubber, latex balloon, foam, charcoal, cloth, paper, cigarette butt and others) and colour (transparent, white, black, blue, green, red, yellow, brown and other). Virgin plastic pellets are the raw plastic material from which larger molded plastic items are made (Wilber, 1987) and usually occur in the form of small rounded shapes $(2-5 \mathrm{~mm}$ ) (Costa et al., 2009). On the other hand, small plastic fragments are the result of successive degradation processes acting on larger plastic debris in the environment (Santos et al., 2009). Results for each specific category were expressed as total number of ingested items, mean $\pm S D$, percentage and frequency of occurrence (F.O.). The F.O. denotes the proportion of specimens from a particular group in which a specific type of item appeared.

It was hypothesized that both the quantities and weight of ingested marine debris did not increase with sea turtles' size and weight, as has been reported in previously studies (Bjorndal et al., 1994; Bugoni et al., 2001). In addition, it was expected that plastics would be prevalent among the ingested items as a consequence of the availability of this type of debris in the environment (Coe and Rogers, 2000; Ivar do Sul and Costa, 2007).

Data were tested for normality (Kolmogorov-Smirnov test) and homogeneity of variances (Levene's test), and, if necessary, logtransformed. Outlier values were removed before the analyses. Pearson's correlation test was performed to establish if quantities and weights of ingested debris were related to the biometric parameters CCL and weight. Two-way analysis of variance (ANOVA) was carried out to evaluate significant differences among specific categories of items and sections of the gastrointestinal tract. One-way ANOVA was performed to detect significant differences among colours of ingested items. If a significant difference was observed, Tukey's post-hoc test was also applied. Statistical significance was set at a probability level of 0.05 .

\subsection{Seabirds}

A total of 35 seabirds were found stranded on the beach between November 1994 and August 2007. The gastrointestinal tract sections (oesophagus, proventriculus, gizzard and intestine) were removed and examined together. Debris items were counted and classified into specific categories (virgin plastic pellet, plastic fragment, polystyrene, hook, fishing rope, anthropogenic wood and cloth). At this time, only virgin plastic pellets had their colour recorded. Results for each specific category of item were expressed as total number and mean \pm SD of ingested items per bird, and as a F.O. for each bird group.

It was hypothesized that plastics would be particularly prevalent amongst the ingested items, reflecting of marine debris composition of the oceans (Ryan, 2008).

The Kruskal-Wallis non-parametric test was used to detect significant differences between colours of ingested virgin plastic pellets as the data were not normally distributed. Student's $t$-test was used to detect significant differences between the number of items ingested by seabirds with trans-equatorial $(n=7)$ and austral $(n=7)$ migratory behaviours.

\section{Results and discussion}

\subsection{Green turtles}

Based on the length of carapace $(\mathrm{CCL})$, all green turtles $(n=34)$ were juveniles $(31.5-56 \mathrm{~cm} ; \bar{x}=40 \pm 6 \mathrm{~cm}$ ) with body weight between 2.5 and $9 \mathrm{~kg}(\bar{x}=5 \pm 2 \mathrm{~kg}, n=17)$. A total of 1602 items of marine debris were found: each individual turtle had ingested between 3 and 134 items $(\bar{x}=47 \pm 32 \mathrm{~cm})$, individually weighing between 0.2 and $69 \mathrm{~g}(\bar{x}=11 \pm 13 \mathrm{~g})$.

In this study, all sampled green sea turtles were found to be contaminated with marine debris. Although the ingestion of debris has been frequently reported for green turtles (Balazs, 1985; Plotkin and Amos, 1990; Bjorndal et al., 1994; Laist, 1997), it has never been observed to reach $100 \%$ of samples as reported here. Studies that were conducted in adjacent areas of the Brazilian and Uruguayan coast have found $60.5 \%$ and $74 \%$ of stranded juvenile green turtles with marine debris in their digestive tracts, respectively (Bugoni et al., 2001; Asaroff et al., 2008). Our findings could indicate that the level of marine debris contamination is increasing.

No significant correlations were found between CCL and the number $(r=0.32 ; p=0.06 ; n=34)$ or weight of items of marine debris $(r=0.31 ; p=0.07)$. In addition, no significant correlations between body weight and either the number $(r=0.05 ; p=0.84$; $n=17)$ or weight of marine debris items $(r=0.02 ; p=0.40)$ were observed. These results corroborate the initial hypothesis that ingestion rates do not increase with the turtle's size and weight. This statement can be explained by their capacity to excrete the majority of marine debris by defecation (Balazs, 1985), which was also confirmed by the present data, since the intestine (with $63 \%$ of items) was significantly more contaminated than stomach (34\%) and oesophagus (3\%) $(F=79.7 ; p=0.04$ and $p=0.00$, respectively).

Speculation about the sources of ingested debris is difficult since green turtles are long-distance migratory animals and hence 
are exposed to debris throughout their life span. Post-hatchling sea turtles feed and grow in the pelagic environment where floating debris accumulates mainly at convergence zones (Carr, 1987). Moreover, juveniles migrate to neritic habitats, feeding in both pelagic and benthic environments, where floating and benthic marine debris can also be ingested. Unfortunately, the prevalence of fragments provides no clues as to their origin. Marine debris can be retained in the gastrointestinal tract for months and can thus persist over multiple life stages (Lutz, 1990). Marine debris sources at the southern Brazilian coast are primary related to beach users (mostly during the summer months), harbour and navigation activities, and runoff from Patos lagoon and Plata River drainage basin (Wetzel et al., 2004).

Plastics accounted for $71 \%$ of the ingested marine debris, followed by fishing-related (21\%) and miscellaneous items (8\%) (Table 1). Among plastics, the majority of items were soft and hard plastic fragments, which together represented $66 \%$ of the total ( $n=1602$ ), while other plastics (virgin plastic pellets and straws) accounted for less than 5\%. Amongst the fishing-related items, fishing line was most frequently observed and accounted for $11 \%$ of the total. In fact, ingested soft plastic fragments were significantly more prevalent than many other categories of items $(F=20.5$; $p<0.05$ ), except hard plastic fragments and fishing line.

The frequency of occurrence (F.O.) of the specific categories of items also demonstrated the prevalence of soft plastic fragments ingested by all turtles ( $n=34)$, followed by hard plastic fragments, fishing line $(n=31)$, ropes $(n=26)$, polystyrene $(n=22)$, rubber $(n=19)$ and foam $(n=18)$. The other categories of items were ingested by less than $50 \%$ of the turtles (Table 1 ).

The predominance of plastics has been pointed out in previous works (Balazs, 1985; Plotkin and Amos, 1990; Bjorndal et al., 1994; Bugoni et al., 2001; Mascarenhas et al., 2004), as well as in this study. However, other diverse types of material were also found in the gastrointestinal tract of sea turtles (Plotkin and Amos, 1990; Balazs, 1985; Tomas et al., 2002). These results partially corroborate the hypothesis that more plastic items are ingested because of their prevalence in marine and coastal environments, which increases the possibility of interactions between plastics and the marine biota. The natural foraging behaviour of juveniles also promotes these interactions, as during this life stage green turtles feed on a wide variety of prey items at the southern Brazilian coast (Bugoni et al., 2003) and do not discriminate plastic debris (Lutz, 1990).

Regarding colour classification, items ingested were primary white (33\%), followed by transparent (26\%), black and blue $(11 \%$ each), green (7\%), brown (4\%), red (3\%) and yellow (2\%). Other colours represented only $3 \%$ of the total. However, no significant differences between colours of ingested items were found $(F=1.09$, $p=0.41$ ). In fact, lab experiments have confirmed that items of different colours are ingested by green turtles (Lutz, 1990). These results indicate that there is no preferential ingestion, at least in relation to colours of debris, by sea turtles.

On Rio Grande do Sul coast, the prevalence of plastics on the monitored beaches has already been reported (Wetzel et al., 2004), supporting the proposed hypothesis. However, in order to validate the hypothesis, more environmental samplings are necessary to establish patterns related to other variables (i.e. size, types of plastics and colours) over larger areas of the globe and representing entire populations of turtles.

Apparently the ingestion of marine debris causes primary sublethal effects rather than death (Bjorndal et al., 1994; Bjorndal, 1997; McCauley and Bjorndal, 1999). This was also found to be true in this study, since 31 turtles died probably for reasons excluding marine debris ingestion. Only three green turtles may have died as a direct consequence of marine debris ingestion. Two specimens had their intestine completely obstructed by plastics, while the third swallowed a large plastic stripe which was too long to pass through the oesophagus causing its blockage. On the other hand, the sub-lethal effects include reduction in food ingestion and assimilation, decreasing in growth rates and increasing time for sexual maturation (Bjorndal, 1997). The last is specially damaging to juveniles, such as the studied specimens, since it may affect future reproductive behaviours. Marine debris ingestion has become a concern in recent decades due to the potential risks to sea turtles, resulting even in demographic implications (Bjorndal, 1997).

\subsection{Seabirds}

Thirty-five specimens of 13 different species from three orders of seabirds (Procellariiformes, $n=18$; Sphenisciformes, $n=9$ and Charadriiformes, $n=8$ ) were sampled (Table 2). Fourteen seabirds

Table 1

Frequency of occurrence and categories of ingested items observed in the different sections of the gastrointestinal tract of green turtles (total number and percentage).

\begin{tabular}{|c|c|c|c|c|c|c|c|}
\hline \multirow[t]{2}{*}{ Categories of items } & \multicolumn{2}{|c|}{ F.O. } & \multicolumn{3}{|l|}{ Sections } & \multirow[b]{2}{*}{ Total } & \multirow[b]{2}{*}{$\%$} \\
\hline & $n$ & $\%$ & Oesophagus & Stomach & Intestine & & \\
\hline Soft plastic & 34 & 100 & 15 & 225 & 334 & 574 & 36 \\
\hline Hard plastic & 31 & 91 & 19 & 133 & 336 & 488 & 30 \\
\hline Straw & 12 & 35 & 0 & 5 & 18 & 23 & 1 \\
\hline Plastic & & & 35 & 366 & 731 & 1132 & 71 \\
\hline Line & 31 & 91 & 9 & 84 & 88 & 181 & 11 \\
\hline Net & 6 & 18 & 0 & 0 & 6 & 6 & 0 \\
\hline Fishing-related items & & & 14 & 138 & 194 & 346 & 21 \\
\hline Rubber & 19 & 56 & 1 & 10 & 23 & 34 & 2 \\
\hline Balloon & 11 & 32 & 1 & 4 & 19 & 24 & 2 \\
\hline Rubber foam & 18 & 53 & 1 & 9 & 14 & 24 & 2 \\
\hline Charcoal & 13 & 38 & 0 & 4 & 11 & 15 & 1 \\
\hline Cloth & 8 & 24 & 1 & 3 & 3 & 7 & 0 \\
\hline Total & & & $\overline{53}$ & 542 & 1007 & 1602 & \\
\hline
\end{tabular}


Table 2

Incidence and number of debris found in the seabirds related with foraging and migratory behaviour.

\begin{tabular}{|c|c|c|c|c|c|c|c|c|}
\hline Order & Species & Common name & $n$ & Incidence of debris & $\%$ & Number of items & Foraging behaviour & Migration pattern \\
\hline \multirow[t]{10}{*}{ Procellariiformes } & Thallasarche melanophoris & Black-browed Albatross & 2 & 2 & 100 & 3 & $\mathrm{SS}^{\mathrm{a}}$ & A \\
\hline & Daption capense & Cape Petrel & 1 & 0 & 0 & 0 & $\mathrm{SS}^{\mathrm{a}}$ & A \\
\hline & Fulmarus glacialoides & Southern Fulmar & 1 & 0 & 0 & 0 & $\mathrm{SS}^{\mathrm{a}}$ & A \\
\hline & Macronectes giganteus & Southern Giant Petrel & 2 & 2 & 100 & 117 & $\mathrm{SS}^{\mathrm{a}}$ & A \\
\hline & Pachytila belcheri & Narrow-billed Prion & 1 & 0 & 0 & 0 & $\mathrm{SS}^{\mathrm{a}}$ & A \\
\hline & Procellaria aequinoctialis & White-chinned Petrel & 1 & 1 & 100 & 2 & $\mathrm{SS}^{\mathrm{a}}$ & A \\
\hline & Puffinus gravis & Greater Shearwater & 4 & 3 & 75 & 5 & $\mathrm{SS}^{\mathrm{a}}$ & $\mathrm{T}$ \\
\hline & Puffinus griseus & Sooty Shearwater & 1 & 1 & 100 & 2 & $\mathrm{PD}^{\mathrm{a}}$ & $\mathrm{T}$ \\
\hline & Puffinus puffinus & Manx Shearwater & 5 & 3 & 60 & 13 & $\mathrm{PP}^{\mathrm{b}}$ & $\mathrm{T}$ \\
\hline & Sub-total & & 18 & 12 & 66 & 142 & & \\
\hline \multirow[t]{2}{*}{ Sphenisciformes } & S. magellanicus & Magellanic Penguin & 9 & 2 & 22 & 2 & $\mathrm{PD}^{\mathrm{a}}$ & A \\
\hline & Sub-total & & 9 & 2 & 22 & 2 & & \\
\hline \multirow[t]{4}{*}{ Charadriiformes } & Larus dominicanus & Southern Black-backed Gull & 4 & 0 & 0 & 0 & $\mathrm{SS}^{\mathrm{a}}$ & A \\
\hline & Larus maculipennis & Brown-hooded Gull & 3 & 0 & 0 & 0 & - & $\mathrm{S}$ \\
\hline & Sterna trudeaui & Snowy-crowned Tern & 1 & 0 & 0 & 0 & $\mathrm{SP}^{\mathrm{c}}$ & $\mathrm{S}$ \\
\hline & Sub-total & & 8 & $\mathbf{0}$ & $\mathbf{0}$ & $\mathbf{0}$ & & \\
\hline Total & & & 35 & 14 & 40 & 144 & & \\
\hline
\end{tabular}

SS: surface seizing; PD: pursuit diving; PP: pursuit plunging; SP: surface plunging; A: austral migration; T: trans-equatorial migration; S: short-distance migration.

a Ryan (1987).

b Griffiths et al. (1982).

c Bugoni and Vooren (2005).

(40\% of total: 12 Procellariiformes and 2 Sphenisciformes) had ingested marine debris. Charadriiformes were not found to be contaminated with marine debris in this survey.

Seabirds are often considered to be effective monitors of the health of marine ecosystems (Mallory, 2008). Among them, one of the most studied groups, the Procellariiformes, seems to provide reliable information about quantities and types of marine debris in the oceans. In southern Brazil a recent study carried out during 1994 and 2005 pointed to the occurrence of marine debris in approximately $38 \%$ of the sampled Procellariiformes (Colabuono et al., 2009). In this study about $66 \%$ of the Procellariiformes were found to be contaminated. This finding reinforces the idea that seabirds on the southern Brazilian coast are at great risk.

A total of 144 items of marine debris were identified. Procellariiformes ingested the vast majority (142) of them. One single specimen of Macronectes giganteus had ingested 117 items (81\%, $n=144$ ), the greatest amount within all sampled seabirds, while the two Spheniscus magellanicus ingested one single item each (Table 2).

According to the scientific literature, Procellariiformes species actually have both the highest loads of ingested plastic per bird and the highest incidence of plastic items (Burger and Gochfeld, 2001; Laist, 1997). This difference has been attributed to the characteristics of the gastrointestinal tract, since the gizzard of Procellariiformes is a distinct organ, separated from the proventriculus by a narrow, angled isthmus (Furness and Monaghan, 1987; Ryan, 1988). Procellariiformes do not regurgitate plastics, whereas other species of seabirds may do so (Mallory et al., 2006).

Plastics accounted for $96 \%$ of the total marine debris, followed by fishing-related items (2\%), anthropogenic wood (1\%) and cloth (1\%). The higher proportion of plastic ingested by seabirds has been reported elsewhere (Day et al., 1985; Azzarello and Van Vleet, 1987; Laist, 1997). These results partially corroborate the hypothesis that seabirds ingest more plastic because this is the most prevalent material found in the oceans (Wilber, 1987; Coe and Rogers, 2000). Among plastics, only fragments (75\%) and virgin plastic pellets (25\%) were identified.

The F.O. of the specific categories of items ingested by Procellariiformes - Procellariidae (petrels) and Diomedeidae (albatrosses) - and Sphenisciformes (penguins) is shown in Fig. 2a. Plastic fragments were ingested only by petrels $(n=9)$, which also ingested virgin plastic pellets $(n=6)$, ropes $(n=1)$ and anthropogenic wood $(n=1)$. The two black-browed albatrosses (Thalassarche melanophoris) ingested a plastic pellet $(n=1)$, polystyrene $(n=1)$ and a fishing hook $(n=1)$. The two magellanic penguins ingested one anthropogenic wood item $(n=1)$ and a piece of cloth $(n=1)$ (Fig. 2a).

Regarding colour classification, virgin plastic pellets $(n=35)$ ingested by petrels and albatrosses were white (60\%), transparent (16\%), gray, yellow ( $9 \%$ each), black and orange (3\% each). Colour evaluation is important since it has been suggested that seabirds may confuse virgin plastic pellets with their natural prey (i.e. fish eggs, algae and others) (Day et al., 1985). Previous works, however, has not established any patterns related to colours of ingested virgin plastic pellets (Ryan, 1987, 2008; Ivar do Sul and Costa, 2007). Likewise, in this study no significant differences between ingested colours $\left(\chi^{2}=6.00, p=0.30\right)$ were detected. These results indicate that there is no selective preference, at least in relation to colours of debris, by seabirds.

Concerning the foraging behaviour of seabirds, it has been also proposed that this may influence marine debris ingestion rates (Azzarello and Van Vleet, 1987), although many other factors should also considered (Spear et al., 1995). Here, seabirds which were contaminated with marine debris are mainly surface-seizing feeders (Ryan, 1987) (Table 2). Seabirds which feed by this method are among the most susceptible to ingest floating plastic debris (Azzarello and Van Vleet, 1987; Ryan, 1987). The other sampled seabirds which feed by different methods ( $P$. puffinus, $P$. griseus and the $S$. magellanicus) had also ingested marine debris, suggesting that all seabirds are susceptible to plastic pollution.

The migratory pattern of seabirds can also give important information related to rates and sources of ingested marine debris. All the seabirds sampled during this study, which had ingested at least one item $(n=14)$, were pelagic long-distance migratory birds (Table 2). So it is quite reasonable to assume that marine debris was ingested in other areas of world and open ocean (Moore et al., 2001; Wilber, 1987). Half of seabirds ( $n=7$ ) were trans-equatorial migrants (Puffinus genus), and the other half austral migrants $(n=7)$ (Table 2). However, no patterns related to the prevalence of 

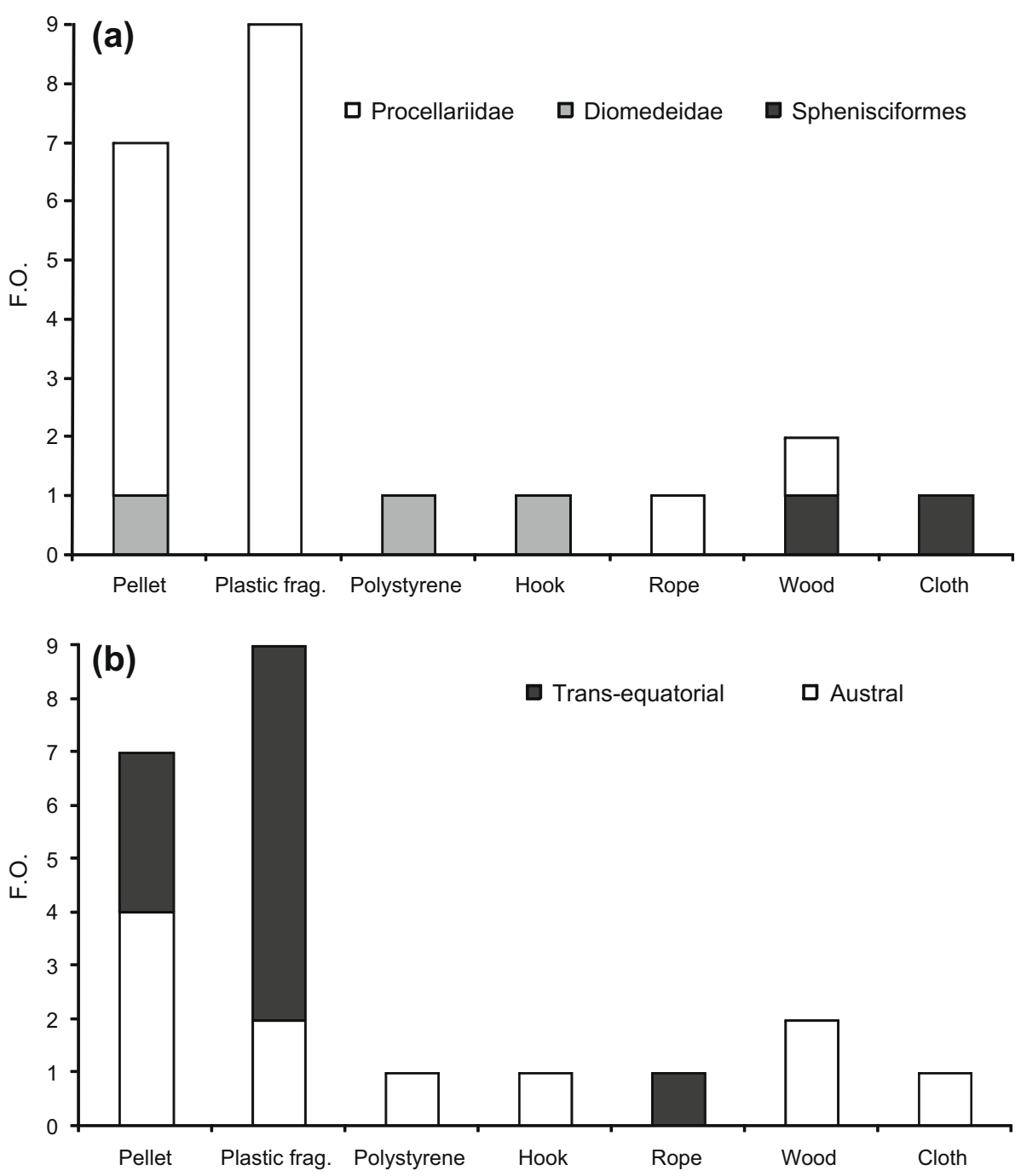

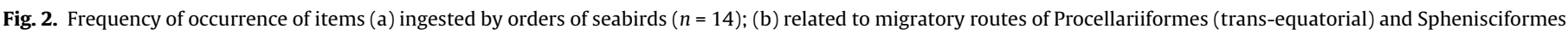
(austral).

a single type of item were detected $(F=2.32, p=0.95)$ comparing these two groups. In fact, it is known that the South and North Oceans did not differ qualitatively in relation to the types of items found (Coe and Rogers, 2000).

The magellanic penguins migrate northwards during austral winter and are threatened by human activities mainly in coastal areas (Pütz et al., 2007). In the last decades, even Antarctica habitats became also contaminated by marine debris, a risk for a huge list of marine endemic species (Van Franeker and Bell, 1988; Ainley et al., 1990). Although none of the sampled penguins in this study contained ingested plastics, previous studies have confirmed that S. magellanicus is also susceptible to plastic debris ingestion (Azevedo and Schiller, 1991). In any case, this species has lower incidence of marine debris when compared to Procellariiformes (Fig. 2b). This pattern can be partially attributed to their foraging behaviour, but their restricted distribution in the globe and the lack of consistent studies with penguins species have also to be taken in consideration.

The Charadriiformes are coastal seabirds which can be found in the southern Brazilian coast during non-breeding season. Their ability to regurgitate indigestible items may be one of the reasons for the absence of ingested marine debris in this study (Azzarello and Van Vleet, 1987). Other studies with Larus dominicanus have also reported a lack of ingestion (Ainley et al., 1990) or even low levels of contamination (13\%) (Ryan, 1987) for these Charadriiformes.

\section{Conclusion}

All stranded green sea turtles sampled during this study were contaminated with marine debris. Comparisons among other studies on adjacent beaches indicated that ingestion of debris by sea turtles is probably an increasing problem on southern Brazilian coast. Plastic fragments were prevalent among other ingested materials and there was no pattern related to colours of ingested items. The establishment of conclusions related to sea turtles preferential ingestion however, should be based on studies with a bigger sample size representing larger areas of the globe. Green turtles can excrete marine debris by defecation, which probably contributes to the occurrence of sub-lethal effects rather than deaths. However, three green turtles have possible died as a direct consequence of marine debris ingestion. Green sea turtles are actually susceptible to ingest marine debris and should be seen as target species when management actions and campaigns are considered.

Procellariiformes were most contaminated with marine debris, as reported elsewhere by several studies. Plastics were also the most ingested items and this may reflect marine debris composition in the open ocean. A pattern related to colours of ingested 
virgin plastic pellets was not observed and further studies are necessary to clarify this question. Surface-seizing feeding species are the most contaminated, but seabirds feeding by other methods are also contaminated, highlighting plastic hazard to these biota.

Finally, the only available method to reduce marine debris ingestion rates is a significant decrease of their sources and inputs to the marine and coastal environments. Thus, legal strategies should be applied to control the generation of human wastes and, simultaneously, efficient policies to ensure their adequate final dumping.

\section{Acknowledgements}

We would like to thank the "Núcleo de Educação e Monitoramento Ambiental - NEMA/RS" for the assistance and the "Museu Oceanográfico Prof. Eliézer C. Rios/FURG” for the samples provided. The authors also thank Dr. John David Bounsfield from Ganesha Associates (http://www.ganeshaassociates.com/) who contributed with the language and scientific editing. G. Fillmann was sponsored by CNPQ (PQ 311459/2006-4) and Paula S. Tourinho by Capes.

\section{References}

Ainley, D.G., Fraser, W.R, Spear, L.B, 1990. The incidence of plastic in the diets of Antarctic seabirds. In: Shomura, R.S., Godfrey, M.L. (Eds.), Proceedings of the Second International Conference on Marine Debris, April 2-7, 1989, Honolulu, Hawaii. US Dep. of Comm., NOAA Tech. Memo. NMFS, NOAA-TM-NMFS-SWFSC154, pp. 682-691.

Asaroff, P.E., Demichelis, S.O., Estrades, A., Fallabrino, A., 2008. Ingesta de residuos antropogénicos por tortuga verde juvenil (Chelonia mydas) en Rocha, Uruguay. II. Congreso Argentino de la Sociedad de Toxicología y Química Ambiental (SETAC).

Azevedo, T.R., Schiller, A., 1991. Notes on the diet and the ingestion of plastic material by the megellanic penguin Spheniscus magellanicus on Santa Catarina Island and mainland (Brazil). Unit. Doc. Zoologie. Seru. Ethol. Psichol. Anim. Universidade Liege, Bélgica. Rapport 457, pp. 1-8.

Azzarello, M.Y., Van Vleet, E.S., 1987. Marine birds and plastic pollution. Marine Ecology Progress Series 37, 295-303.

Balazs, G., 1985. Impact of ocean debris on marine turtles: entanglement and ingestion. In: Shomura, R.S., Yoshida, H.O. (Eds.), Proceedings of the Workshop on the Fate and Impact of Marine Debris, 26-29 November 1984, Honolulu, Hawaii. US Dep. of Comm., NOAA Tech. Memo. NMFS, NOAA-TM-NMFS-SWFC54, pp. 387-429.

Bjorndal, K.A., 1997. Foraging ecology and nutrition in sea turtles. In: Lutz, P.L., Musick, J.A. (Eds.), The Biology of Sea Turtles. CRC Marine Science Series, CRC Press, Boca Raton, Florida, pp. 199-231.

Bjorndal, K.A., Bolten, A.B., Lagueux, C.J., 1994. Ingestion of marine debris by juvenile sea turtles in Coastal Florida habitats. Marine Pollution Bulletin 28, 154-158.

Bugoni, L., Vooren, C.M., 2005. Distribution and abundance of six Tern species in southern Brazil. Waterbirds 28, 110-119.

Bugoni, L., Krause, L., Petry, M.V., 2001. Marine debris and human impacts on sea turtles in southern Brazil. Marine Pollution Bulletin 42, 1330-1334.

Bugoni, L., Krause, L., Petry, M.V., 2003. Diet of sea turtles in southern Brazil. Chelonian Conservation and Biology 4, 685-688.

Burger, J., Gochfeld, M., 2001. Effects of chemicals and pollution on seabirds. In: Burger, J., Schreiber, E.A. (Eds.), Biology of Marine Birds. CRC Marine Biology Series, CRC Press, Boca Raton, Florida, pp. 485-526.

Carr, A., 1987. Impact of nondegradable marine debris on the ecology and survival outlook of sea turtles. Marine Pollution Bulletin 18, 352-356.

Coe, J.M., Rogers, D.B., 2000. Marine Debris: Sources, Impacts and Solutions. Springer-Verlag, New York.

Colabuono, F.I., Barquete, V., Domingues, B.S., Montone, R.C., 2009. Plastic ingestion by Procellariiformes in southern Brazil. Marine Pollution Bulletin 58, 93-96.

Costa, M.F., Ivar do Sul, J.A., Silva-Cavalcanti, J.S., Araújo, M.C.B., Spengler, A., Tourinho, P.S., 2009. On the importance of size of plastic fragments and pellets on the strandline: a snapshot of a Brazilian beach. Environmental Monitoring and Assessment, doi:10.1007/s10661-009-1113-4

Day, R.H., Wehle, D.H.S., Coleman, F.C., 1985. Ingestion of plastic pollutants by marine birds. In: Shomura, R.S., Yoshida, H.O. (Eds.), Proceedings of the Workshop on the Fate and Impact of Marine Debris, November 27-29, 1984 Honolulu, Hawaii. US Dep. of Comm., NOAA Tech. Memo. NMFS, NOAA-TMNMFS-SWFC-54, pp. 344-386.

Esteves, L.S., Toldo Jr., E.E., Dillenburg, S.R., Tomazelli, L.J., 2002. Long- and shortterm coastal erosion in southern Brazil. Journal of Coastal Research 36, 273282.

Furness, R.W., Monaghan, P., 1987. Seabirds Ecology. Chapman and Hall, New York Griffiths, A.M., Siegfried, W.R., Abrams, R.W., 1982. Ecological structure of a pelagic seabird community in the southern Ocean. Polar Biology 1, 39-46.

Ivar do Sul, J.A., Costa, M.F., 2007. Marine debris review for Latin America and the wider Caribbean region: from the 1970s until now, and where do we go from here? Marine Pollution Bulletin 54, 1087-1104.

Laist, D.W., 1997. Impacts of marine debris: entanglement of marine life in marine debris including a comprehensive list of species with entanglement and ingestion records. In: Coe, J.M., Rogers, D.B. (Eds.), Marine Debris: Sources, Impacts and Solutions, pp. 99-139.

Lutz, P.L., 1990. Studies on the ingestion of plastic and latex by sea turtles. In: Shomura, R.S., Yoshida, H.O. (Eds.), Proceedings of the Workshop on the Fate and Impact of Marine Debris, Honolulu, pp. 719-735.

McCauley, S.J., Bjorndal, K.A., 1999. Conservation implications of dietary dilution from debris ingestion: Sublethal effects in post-hatchling loggerhead sea turtles. Conservation Biology 13, 925-929.

Mallory, M.L., 2008. Marine plastic debris in northern fulmars from the Canadian high Arctic. Marine Pollution Bulletin 56, 1501-1504.

Mallory, M.L., Roberston, G.J., Moenting, A., 2006. Marine plastic debris in northern fulmars from Davis Strait, Nunavut, Canada. Marine Pollution Bulletin 52, 813815.

Mascarenhas, R., Santos, R., Zeppelini, D., 2004. Plastic debris ingestion by sea turtle in Paraiba, Brazil. Marine Pollution Bulletin 49, 354-355.

Moore, C.J., Moore, S.L., Leecaster, M.K., Weisberg, S.B., 2001. A comparison of plastic and plankton in the north Pacific central gyre. Marine Pollution Bulletin 42, 1297-1300.

Pierce, K.E., Harris, R.J., Larned, L.S., Pokras, M.A., 2004. Obstruction and starvation associated with plastic ingestion in a Northern gannet Morus bassanus and a Greater shearwater Puffinus gravis. Marine Ornithology 32, 187-189.

Plotkin, P., Amos, A., 1990. Effects of anthropogenic debris on sea turtles in the northwestern Gulf of Mexico. In: Shomura, R.S., Yoshida, H.O. (Eds.) Proceedings of the Workshop on the Fate and Impact of Marine Debris, Honolulu, pp. 736-743.

Pütz, K., Schiavini, A., Rey, A., Lüthi, B., 2007. Winter migration of magellanic penguins (Spheniscus magellanicus) from the southernmost distributional range. Marine Biology 152, 1227-1235.

Ryan, P.G., 1987. The incidence and characteristics of plastic particles ingested by seabirds. Marine Pollution Bulletin 23, 175-206.

Ryan, P.G., 1988. Intraspecific variation in plastic ingestion by seabirds and the flux of plastic through seabird populations. Condor 90, 446-452.

Ryan, P.G., 2008. Seabirds indicate changes in the composition of plastic litter in the Atlantic and south-western Indian Oceans. Marine Pollution Bulletin 56, 14061409.

Santos, I.R., Friedrich, A.C., Ivar do Sul, J.A., 2009. Marine debris contamination along undeveloped tropical beaches from northeast Brazil. Environmental Monitoring and Assessment 148, 455-462.

Soto, J.M.R., Beheregaray, R.C.P., 1997. Chelonia mydas in the northern region of the Patos lagoon, South Brazil. Marine Turtle Newsletter 77, 10-11.

Spear, L.B., Ainley, D.G., Ribic, C.A., 1995. Incidence of plastic in seabirds from the tropical Pacific, 1984-91 - relation with distribution of species, sex, age, season, year and body-weight. Marine Environmental Research 40, 123-146.

Tomas, J., Guitart, R., Mateo, R., Raga, J.A., 2002. Marine debris ingestion in loggerhead sea turtles, Caretta caretta from the western Mediterranean. Marine Pollution Bulletin 44, 211-216.

Van Franeker, J.A., Bell, P.J., 1988. Plastic ingestion by petrels breeding in Antarctica. Marine Pollution Bulletin 19,672-674.

Vooren, C.M., 1997. Sea and shore birds. In: Seeliger, U., Odebrecht, C., Castello, J.P. (Eds.), Subtropical Convergence Environment: The Coast and Sea in the Southwestern Atlantic, Berlin, pp. 154-158.

Wetzel, L., Fillmann, G., Niencheski, L.F.H., 2004. Litter contamination processes and management perspectives on the southern Brazilian coast. International Journal of Environment and Pollution 21, 153-165.

Wilber, R.J., 1987. Plastic in the North Atlantic. Oceanus 30, 61-68. 